\title{
Encouraging Patient-Centered Care by Including Quality-of-Life Questions on Pre-Encounter Forms
}

\author{
Becky A. Purkaple, BA, BS \\ James W. Mold, MD, MPH ${ }^{2}$ \\ Sixia Cben, $\mathrm{PbD}^{3}$
}

'University of Oklahoma College of Medicine, Oklahoma City, Oklahoma

${ }^{2}$ Department of Family and Preventive Medicine, University of Oklahoma Health Sciences Center, Oklahoma City, Oklahoma

${ }^{3}$ Department of Biostatistics and Epidemiology, University of Oklahoma, Oklahoma City, Oklahoma
Conflicts of interest: authors report none.

\section{CORRESPONDING AUTHOR}

Becky Purkaple, BA, MS4 4321 North Shartel Avenue Oklahoma City, OK 73118 becky-purkaple@ouhsc.edu

\begin{abstract}
PURPOSE Patient participation in clinical decision making improves outcomes, including quality of life (QOL), but the typical problem-oriented approach may impede consideration of functional goals. We wondered if patients could encourage primary care physicians to pay attention to their $\mathrm{QOL}$ goals by writing them on pre-encounter forms.
\end{abstract}

METHODS We conducted a randomized controlled trial comparing the impact of 2 different pre-visit questionnaires on the content of patient-physician encounters in a family medicine practice at an academic medical center. Using investigatorblinded block randomization, we arranged for 8 faculty and 8 resident physicians to participate in 2 intervention and 2 control videotaped encounters each for a total of 64 encounters. The intervention questionnaire included questions about $\mathrm{QOL}$ goals and concerns, while the control questionnaire asked about symptoms. Videotapes were reviewed to determine whether the patients' QOL goals were mentioned and whether they were used in decision making. We also scored encounters using Modified Flanders Interaction Analysis, which assesses and codifies patient and physician communication, and the Modified Carkhuff-Truax Scale, which measures empathy, attending, congruence, and positive regard.

RESULTS Patients were able to record QOL goals and concerns, but $\mathrm{QOL}$ issues were mentioned in only 2 of the 64 encounters, once by a patient and once by a physician. In neither case was this information used in decision making. More empathy was expressed by physicians during control encounters $(P=.03)$.

CONCLUSIONS Patients were able to articulate their QOL goals on paper, but that did not prime them or their physicians to alter the process or content of the clinical encounters. In fact, providing QOL information was associated with reduced physician empathy.

Ann Fam Med 2016;14:221-226. doi: 10.1370/afm.1905.

\section{INTRODUCTION}

$\mathrm{P}$ atient participation in clinical decision making improves outcomes, including quality of life (QOL). ${ }^{1-7}$ Yet physicians tend to focus on diseases and symptoms rather than on patient-oriented outcomes such as the ability to participate in meaningful life activities. ${ }^{8-9}$ This problem-oriented approach is the one taught in most medical schools and reinforced by coding and billing requirements, clinical practice guidelines, and electronic medical record systems. ${ }^{10}$ Such an indirect approach to goal attainment assumes that patients' health goals will be achieved if their problems can be solved or ameliorated, which may or may not be the case. It has been shown that verbal agreement between patients and physicians concerning what problems need to be addressed facilitates problem-solving and leads to better outcomes. ${ }^{11-12}$ Perhaps a more direct, patient-centered approach is needed in order to improve clinical decisionmaking and patient QOL.

We wondered if patients could encourage their primary care physicians to use a more direct, patient-centered approach to care by using routine pre-encounter forms to alert their physicians to the activities important to 
them. Interventions that include activation of clinicians by preconsultation questionnaires have been shown to significantly influence the patient-physician encounter and promote positive outcomes. ${ }^{4}$ If patients wrote down their QOL goals and concerns, would their physicians be more likely to address them directly and consider them during the decision-making process?

\section{METHODS}

In an academic family medicine practice run by the Department of Family and Preventive Medicine, University of Oklahoma Health Sciences Center, Oklahoma City, Oklahoma, we conducted a randomized controlled trial comparing the impact of 2 versions of a pre-visit questionnaire on the content of physicianpatient encounters. Both versions included questions about recent health care visits, changes in medications or social stressors, and, if applicable, receipt of recommended diabetes and asthma care. The form completed by control patients included the single-question, "Which symptoms or problems are bothering you the most lately?" The form given to the intervention group included the following 3 questions:

- "What things are you unable to do as a result of your health problems?"

- "What other things would you like to be able to do that you can't do now?"

- "What activities make life worthwhile for you (that you wouldn't want to have to give up)?"

Eight faculty and 8 third-year residents agreed to have randomly selected patient encounters videotaped Four encounters were recorded for each clinician for a total of 64 encounters. Encounters were randomized in blocks by physician, so that each physician participated randomly in 2 intervention encounters and 2 control encounters.

The medical center's Institutional Review Board approved the study. Clinicians were told that the purpose of the study was to determine whether "patients' responses to pre-visit survey questions influence the content and process of encounters." After this explanation and the opportunity to ask questions, each clinician signed an informed consent document.

Videotaping of patient encounters is a routine part of the training of resident physicians in this department. Adult patients (aged over 18 years) were recruited following the usual department training protocol, obtaining their consent to have their visit videotaped for both educational and research purposes. Consecutive patients assigned to participating physicians were approached throughout the week without prior screening as to the reason for their visit. Each patient was given information about the study by the first author (B.A.P.) verbally and in written form, and consent was obtained. The nurses were handed sealed envelopes in a randomly generated sequence with identification numbers for the physician and encounter. The researcher who scored the encounters was not a part of this randomization process and had no direct knowledge of which survey was provided to the patient at the time of the encounter, during the coding process, or during the analysis of the data. The randomization code was broken after all analyses were completed.

The first author evaluated videotaped encounters to determine whether the patient's QOL goals or concerns were specifically discussed at any time during the encounter (yes/no) and/or during discussions pertaining to clinical decision-making (yes/no). Six videotapes were flagged because they included words pertinent to the study such as "goals" and "quality of life" or were otherwise equivocal. These tapes were also reviewed in their entirety by another author (J.W.M.), who was also blinded to group assignment.

The contents of the physician-patient interactions were scored using 2 modalities, Modified Flanders Interaction Analysis and the Modified Carkhuff-Truax Scale. Flanders Interaction Analysis was originally developed to assess teacher communication in the classroom $^{13}$ and has been widely used since in the educational sphere since. ${ }^{14,15}$ It has been adapted for use as a tool to measure health care provider communication during patient encounters. ${ }^{16-18}$ The assessment captures the content at 3 -second intervals using a 10 -option categorical model (Table 1). From that data, the percentage of patient and physician talk time can be computed. The Modified Carkhuff-Truax Scale was used to analyze positive regard, attending, congruence, and empathy, each on a 0 to 5 scale. This scale was developed for analyzing empathy in training psychologists

\section{Table 1. Modified Flanders Assessment Tool}

1. Doctor responds to feelings

2. Doctor praises or encourages

3. Doctor uses patient's ideas

4a. Doctor asks open-ended question

4b. Doctor asks closed-ended question

5. Doctor gives information

6. Doctor gives instructions

7. Doctor criticizes or justifies his or her authority

8. Patient responds to doctor

9. Patient initiates (question or information)

10. Silence or confusion

Note: For this study, categories 1 through 7 were combined to determine total physician talk time, and categories 8 and 9 were combined for patient talk time. More detailed analyses of the categories were not used. 
and counselors ${ }^{19-21}$ and has been modified for use in the health care setting. ${ }^{22-24}$ All of the videotapes were reviewed by B.A.P., who was trained by a faculty member who routinely scored resident physician encounters in the department. The training consisted of B.A.P. observing the faculty member scoring encounters that were not associated with the study, the faculty member watching B.A.P. score additional videotapes and commenting on her performance, and B.A.P. scoring other encounters that the faculty member already scored, after which her results were compared with the faculty member's results.

We used the McNemar Test to compare differences in rates of inclusion of QOL information between control and intervention encounters and paired the ordinal measures from Modified Flanders Interaction Analysis and the Modified Carkhuff-Truax Scale for each physician by encounter type (control or intervention). We then calculated the mean score for each encounter type and the difference between the 2 for each physician. Using SPSS (IBM Corporation), we then analyzed the data, using the Wilcoxon Signed Rank Test for the Carkhuff-Truax scores and a paired $t$-test for Modified Flanders Interaction Analysis, to compare the control and intervention groups. To confirm our calculations, we performed a linear mixed model analysis on the raw data that took into account clustering within physicians. Finally, we completed a quantile regression with random effect to confirm the results. The 3 modalities produced consistent results.

\section{Table 2. Comparison and Selected Examples of Information Provided} on Pre-Visit Forms

\begin{tabular}{|c|c|}
\hline Questions & Answers (Examples) \\
\hline \multicolumn{2}{|l|}{ Control group } \\
\hline $\begin{array}{l}\text { Which symptoms or prob- } \\
\text { lems are bothering you } \\
\text { the most lately? }\end{array}$ & $\begin{array}{l}\text { Leg, pain with walking } \\
\text { Back pain, back spasms } \\
\text { Fibromyalgia; arthritis } \\
\text { Dizziness, neuropathy } \\
\text { Diabetes, foot pain } \\
\text { Eyes floaters, stomach-diarrhea } \\
\text { ADHD medication } \\
\text { Bone infection } \\
\text { Toenail fungus }\end{array}$ \\
\hline \multicolumn{2}{|l|}{ Intervention Group } \\
\hline $\begin{array}{l}\text { 1. What things are you } \\
\text { unable to do as a result of } \\
\text { your health problems? }\end{array}$ & $\begin{array}{l}\text { Flowering/gardening, taking shower by self } \\
\text { Get comfortable, get dressed, take shower, cook, walk, roll over } \\
\text { Most things, sadly; anything with exertion }\end{array}$ \\
\hline $\begin{array}{l}\text { 2. What other things would } \\
\text { you like to be able to do } \\
\text { that you can't do now? }\end{array}$ & $\begin{array}{l}\text { Get dressed, stand and walk to cook } \\
\text { Have a better memory for everyday things, school life, etc. } \\
\text { Cooking on my own, doing things my way when I want to }\end{array}$ \\
\hline $\begin{array}{l}\text { 3. What activities make life } \\
\text { worthwhile for you (that } \\
\text { you wouldn't want to have } \\
\text { to give up)? }\end{array}$ & $\begin{array}{l}\text { Doing my own thing, go to bedroom from bathroom } \\
\text { Taking care of my son, bathing self, being able to walk outside } \\
\text { Spending time with loved ones }\end{array}$ \\
\hline
\end{tabular}

\section{RESULTS}

The patients recruited for this study had a mean age of 49.9 years with a standard deviation of 15.1 years and were $64.1 \%$ female, $51.6 \%$ Caucasian, $42.2 \%$ African American, and 9.1\% Hispanic. In the control group, symptoms were reported on the pre-encounter forms by 24 of 32 patients $(75 \%)$. In the intervention group, in response to the first question, "What things are you unable to do as a result of your health problems?" 9 respondents $(24 \%)$ reported that they had no limitations. Seven patients $(21.8 \%)$ reported that they were unable to walk or exercise and desired to do so. An overlapping 7 reported inability to perform activities of daily living or instrumental activities of daily living such as "using the bathroom" and "get comfortable, get dressed, takes shower, cook." Other responses referenced the inability to do specific activities ("I can't swim") or were more general ("walking long hurts bad/ fall down a lot").

The second question, "What other things would you like to be able to do that you can't do now?" had the highest non-response rate (27\%). Seven patients (21.9\%) indicated that there were no activities they wanted and were unable to do. Completed responses most often focused on desired physical activities, such as "take short walks without chronic pain, sit through a whole movie, cook on my own," but they were occasionally more general, such as "doing things my way when I want to." Two patients $(6.3 \%)$ left questions 1 and 2 completely blank.

The third question was the most likely of the 3 to be answered, with 27 patients $(84.4 \%)$ responding. The most commonly reported meaningful life activities were in the area of interacting with family and friends (Table 2). For example, 1 patient wrote, "play with my grandson-he is 5 years old-I really am not able to do much with him." Physical activities were also mentioned frequently. Seven patients $(21.9 \%)$ listed things like "walking, exercise, sex, etc." and "being able to walk outside." No patients responded to this question with "nothing." Only 4 questionnaires (12.5\%) had no response to any of the QOL questions. More examples are shown in Table 2.

Symptoms were discussed in every encounter in both control 
Table 3. A Comparison of Outcome Measures by Group

\begin{tabular}{|c|c|c|c|}
\hline Outcome Measure & $\begin{array}{l}\text { Control } \\
(n=32)\end{array}$ & $\begin{array}{l}\text { Intervention } \\
\quad(n=32)\end{array}$ & $\begin{array}{c}P \\
\text { Value }\end{array}$ \\
\hline Patient's QOL goals or concerns were mentioned, No. & 0 & 2 & NSa \\
\hline $\begin{array}{l}\text { Patient's QOL goals or concerns were discussed } \\
\text { during clinical decision-making, No. }\end{array}$ & 0 & 0 & NSa \\
\hline \multicolumn{4}{|l|}{ Modified Carkhuff-Truax Scale Scores } \\
\hline Empathy, mean score & 2.92 & 2.53 & .01 \\
\hline Attendance, mean score & 2.75 & 2.88 & NSb \\
\hline Congruence, mean score & 2.69 & 2.81 & NSb \\
\hline Positive regard, mean score & 2.66 & 2.50 & NSb \\
\hline \multicolumn{4}{|l|}{ Modified Flanders Assessment Tool Results, \% (SD) } \\
\hline Portion of visit taken up with physician talk & $48.0(0.11)$ & $48.6(0.15)$ & NSc \\
\hline Portion of visit taken up with patient talk & $38.8(0.11)$ & $36.8(0.14)$ & NSc \\
\hline \multicolumn{4}{|l|}{$\mathrm{NS}=$ not significant; $\mathrm{QOL}=$ quality of life } \\
\hline $\begin{array}{l}\text { aMcNemar test. } \\
\text { bWilcoxon signed rank test. } \\
\text { 'Paired } t \text {-tests. }\end{array}$ & & & \\
\hline
\end{tabular}

trol group scored higher on the empathy subscore $(P=0.0136)$ than physicians in the intervention group (Table 3 ).

\section{DISCUSSION}

\section{Effect of the Intervention on Patient Behaviors}

Patients seemed ready and able to provide personal QOL goals and concerns on the forms. Previous studies have shown that the use of questionnaires and prompt sheets increases the number of questions patients ask. ${ }^{25}$ Furthermore, they have even been shown to change communication patterns and help allow patients to be

and intervention groups. When control patients listed symptoms, they were discussed. When they didn't, in both control and intervention encounters, they were elicited and discussed. QOL issues, however, were mentioned in only 2 of the 32 intervention encounters $(6.3 \%$; Table 3$)$. In the first, the patient remarked, "I'll get up, and I can't even walk-my house isn't even that big, but I can't even walk from one end of the house to the other without getting that, like, you know, if-Idon't-sit-down-I'm-going-to-fall-down feeling, but you know that's my biggest complaint." In response, the physician focused on blood glucose control: "That [glycemic control] is the only way to do it. 'Cause really, your body has the ability to heal itself, but the thing is, it is really handicapped if your blood sugars stay high cause it just can't heal."

The second case was one in which the physician had spent a great deal of time explaining the importance of tight glycemic control. The physician then glanced at the intervention intake form and said, "So I think one way or another, we-I think-can improve your blood sugar levels without messing up your quality of life. That would be the goal in all of this." The patient had written that the activities that make life worthwhile for him included "working and playing with grandkids." In neither case was QOL information specifically used for clinical decision making.

Results of Modified Flanders Interaction Analysis showed no significant difference in the amount of physician talk time or patient talk time between the intervention and control groups. The Carkhuff-Truax also showed no statistically significant difference in the attendance, congruence, or positive regard scores between the groups. However, physicians in the con- more active in the encounters both in oncology and in primary care. ${ }^{26,27}$ In our study, however, QOL was mentioned by a patient in only 1 encounter and even then was not used in clinical decision making. This suggests that it is the QOL information itself that is hard to incorporate. This could have been because patients prefer that their physicians open the QOL discussion or because there was no logical place to bring up meaningful life activities within the standard medical encounter. In addition to completing a pre-visit questionnaire, patients may need training and possibly even pre-visit coaching in order to be able to adopt this new behavior.

\section{Effects of the Intervention on Physician Behaviors}

Only 1 physician mentioned quality of life, and as mentioned above, he merely used the words "quality of life" while referencing glycemic control. In that case, the comment was unrelated to the information provided by the patient and was not used for clinical decision making. This failure to address QOL concerns could be due to a lack of utilization of the intake forms, which were read by physicians with varying degrees of interest. Some spent time and even remarked to the patients the importance of reading the intake form. During control encounters, however, all physicians used the symptoms reported by the patient, which suggests that they were paying attention to the forms.

Since pre-visit questionnaires and prompt sheets have been shown to be effective in other studies, $4,25-27$ the method of information delivery cannot be the only barrier to incorporating QOL information into the patient-physician encounter in our study. More likely, physicians did not know how to incorporate patient 
QOL goals into the standard medical approach in which goals are assumed to be attained when problems have been successfully addressed. This is supported by the Carkhuff-Truax scale empathy score results, which showed significantly less empathy in the intervention group than in the control group. That physicians struggle to incorporate nonstandard information into patient encounters has been documented by others. ${ }^{28,29}$ The information provided about goals may have made some physicians uncomfortable and thus less able to express empathy. Further investigation is needed to clarify the reason for reduced expressions of empathy during intervention encounters, but it does illustrate that the intervention had an effect, albeit a negative one, on physician behavior.

Since physicians were unable to incorporate QOL information, additional measures will evidently be required to encourage physicians to address patients' QOL goals directly. Training physicians would likely be more challenging than training patients, given physicians' extensive indoctrination in the problemoriented approach as well as the many components of the health care system that reinforce problem-oriented thinking and behaviors.

\section{Importance of the Topic}

There are several reasons to continue pursuing this line of research. First, patient goal setting improves outcomes in all settings where it has been studied..$^{1-7}$ More research is needed to understand how to encourage goal-setting in primary care. Since the content of the patient-physician encounter is one key to a patientcentered primary care system ${ }_{,}{ }^{4}$ it may be necessary to reconceptualize the encounter itself. ${ }^{5,30}$

Second, the current problem-oriented approach has significant limitations. ${ }^{6} \mathrm{~A}$ disease-focused treatment plan does not always take into account patient preferences or needs. Fifty percent of Medicare beneficiaries are receiving 5 or more medications for their chronic illnesses based on problem-oriented guidelines, which may effectively treat the diseases but fail to address the issues most pressing to patients and even cause more harm than benefit. ${ }^{31-34}$

More and more patients want to be involved in medical decision making, and greater access to information makes them better able to participate. Allowing patients to express their personal goals creates a more equal interaction between patient and physician, in which both individuals are experts, one in medicine and the other in the desired outcomes of treatment. ${ }^{3}$ When patients are key participants, they will likely be more willing to enter into honest communication, broadening the conversation and opening up a broader range of diagnostic and therapeutic options. ${ }^{35,36}$ In this model, patients take an active role in making decisions about treatment strategies and thus their overall health. Thus, a goal-directed approach is a reasonable way to facilitate patient-centered care. ${ }^{37}$

\section{Limitations}

Our study and its results could have been limited by a number of factors. The study was conducted in a single academic practice, and all of the physician participants were either faculty or residents in the same department. Academic centers differ from private and public clinics, and those settings were not assessed in this study. Physicians and patients knew that the encounters were videotaped, which could have affected the characteristics of the encounters, but, if so, we would have expected it to influence encounters in the direction of an intervention effect, which was not what was seen.

Patients were able to articulate their QOL goals on paper in most cases, but that did not change the content or characteristics of the subsequent clinical encounters except possibly to reduce physician empathy.

To read or post commentaries in response to this article, see it online at http://www.annfammed.org/content/14/3/221.

Key words: patient-centered care; goal-directed care; family medicine; general practice; quality of life

Submitted August 18, 2015; submitted, revised, December 14, 2015; accepted December 29, 2015.

Funding support: This study was funded by the Department of Family and Preventive Medicine at the University of Oklahoma Health Sciences Center.

Acknowledgments: The authors thank Laine H. McCarthy, MLIS, for assistance with literature searching. She is supported by Oklahoma Shared Clinical \& Translational Resources, funded by grant NIGMS U54GM104938, National Institute of General Medical Sciences, National Institutes of Health. Partial funding provided by National Institutes of Health, National Institute of General Medical Sciences (Grant 1 U54GM104938), anIDeA-CTR to the University of Oklahoma Health Sciences Center.

\section{References}

1. Elwyn G, Edwards A, Kinnersley P. Shared decision-making in primary care: the neglected second half of the consultation. $\mathrm{Br} J \mathrm{Gen}$ Pract. 1999;49(443):477-482.

2. Stewart MA. Effective physician-patient communication and health outcomes: a review. CMAJ. 1995;152(9):1423-1433.

3. Fried TR, Tinetti M, Agostini J, lannone L, Towle V. Health outcome prioritization to elicit preferences of older persons with multiple health conditions. Patient Educ Couns. 2011;83(2):278-282.

4. Griffin SJ, Kinmonth AL, Veltman MW, Gillard S, Grant J, Stewart M. Effect on health-related outcomes of interventions to alter the interaction between patients and practitioners: a systematic review of trials. Ann Fam Med. 2004;2(6):595-608.

5. Constand MK, MacDermid JC, Dal Bello-Haas V, Law M. Scoping review of patient-centered care approaches in healthcare. BMC Health Serv Res. 2014;14:271. 
6. Tinetti ME, Bogardus ST Jr, Agostini JV. Potential pitfalls of diseasespecific guidelines for patients with multiple conditions. $N$ Engl J Med. 2004;351(27):2870-2874.

7. Ertzgaard P, Ward AB, Wissel J, Borg J. Practical considerations for goal attainment scaling during rehabilitation following acquired brain injury. J Rehabil Med. 2011;43(1):8-14.

8. Mold JW, Blake GH, Becker LA. Goal-oriented medical care. Fam Med. 1991;23(1):46-51.

9. Street RL Jr, Liu L, Farber NJ, et al. Provider interaction with the electronic health record: the effects on patient-centered communication in medical encounters. Patient Educ Couns. 2014;96(3):315-319.

10. Mold JW, Hamm R, Scheid D. Evidence-based medicine meets goal-directed health care. Fam Med. 2003;35(5):360-364.

11. Starfield B, Steinwachs D, Morris I, Bause G, Siebert S, Westin C. Patient-doctor agreement about problems needing follow-up visit. JAMA. 1979;242(4):344-346.

12. Starfield B, Wray C, Hess K, Gross R, Birk PS, D'Lugoff BC. The influence of patient-practitioner agreement on outcome of care. Am J Public Health. 1981;71(2):127-131.

13. Flanders NA. Interaction Analysis in the Classroom: A Manual for Observers. Ann Arbor, MI: University of Michigan; 1964.

14. Amatari VO. The instructional process: a review of Flanders' Interaction Analysis in a classroom setting. Internat'l I Second Ed. 2015;3(5):43-49.

15. Lambert $P$, William L. Goodwin, and Richard F Roberts. A note on the use of Flanders Interaction Analysis. J Educ Res. 1965;58(5): 222-224.

16. Foster PJ. Verbal participation and outcomes in medical education. A study of third-year clinical discussion groups. Annu Conf Res Med Educ. 1979;18:233-238.

17. Kishi KI. Communication patterns of health teaching and information recall. Nurs Res. 1983;32(4):230-235.

18. Lyon, Harold C et al. Improvements in teaching behavior at two German Medical schools resulting from a modified Flanders Interaction Analysis Feedback Intervention process. Med Teach. 204;36(10) (2014):903-911.

19. Carkhuff RR, Berenson BG. Beyond Counseling and Therapy. New York, NY: Holt, Rinehart \& Winston; 1967; 26-29.

20. Sanson-Fisher B. A multidimensional scaling analysis of empathy. J Clin Psych. 1978;34(4):971-977.

21. Watts GP. The Carkhuff Discrimination Scale as a predictor of accurate perception of others. J Consult Clin Psychol. 1973:41(2):202.

22. Jarski RW, Gjerde CL, Bratton BD, Brown DD, Matthes SS. A comparison of four empathy instruments in simulated patient-medical student interactions. J Med Ed. 1985;60(7): 545-551.
23. Gleber JM. Interpersonal communications skills for dental hygiene students: a pilot training program. J Den Hygiene. 1995;69(1):19-30.

24. Layton JM, Wykle MH. A validity study of four empathy instruments. Res Nurs Health. 1990;13(5):319-325.

25. Brown R, Butow PN, Boyer MJ, Tattersall MH. Promoting patient participation in the cancer consultation: evaluation of a prompt sheet and coaching in question-asking. Br J Cancer. 1999;80(1-2):242-248.

26. Albada A, van Dulmen S, Ausems MGEM, Bensing JM. A previsit website with question prompt sheet for counselees facilitates communication in the first consultation for breast cancer genetic counseling: findings from a randomized controlled trial. Genet Med. 2012;14(5):535-542.

27. Little P, Dorward M, Warner G, et al. Randomised controlled trial of effect of leaflets to empower patients in consultations in primary care. BMJ. 2004;328(7437):441.

28. Lang F, Floyd MR, Beine KL, Buck P. Sequenced questioning to elicit the patient's perspective on illness: effects on information disclosure, patient satisfaction, and time expenditure. Fam Med. 2002;34(5):325-330.

29. Zimmermann C, Del Piccolo L, Finset A. Cues and concerns by patients in medical consultations: a literature review. Psychol Bull. 2007;133(3):438-463.

30. Mold JW. An alternative conceptualization of health and health care: its implications for geriatrics and gerontology. Educ Gerontol. 1995;21(1):85-101.

31. Kaufman DW, Kelly JP, Rosenberg L, Anderson TE, Mitchell AA. Recent patterns of medication use in the ambulatory adult population of the United States: the Slone survey. JAMA. 2002;287(3):337-344.

32. Berry DC, Michas IC, Gillie T, Forster M. What do patients want to know about their medicines, and what do doctors want to tell them? A comparative study. Psychol Health. 1997;12(4):467-480.

33. Price EL, Bereknyei S, Kuby A, Levinson W, Braddock CH III. New elements for informed decision making: a qualitative study of older adults' views. Patient Educ Couns. 2012;86(3):335-341.

34. Ditto PH, Druley JA, Moore KA, Danks JH, Smucker WD. Fates worse than death: the role of valued life activities in health-state evaluations. Health Psychol. 1996;15(5):332-343.

35. Mold JW, Hamm RM, McCarthy LH. The law of diminishing returns in clinical medicine: how much risk reduction is enough? J Am Board Fam Med. 2010;23(3):371-375.

36. Mold JW, McCarthy L. Pearls from geriatrics, or a long line at the bathroom. J Fam Pract. 1995;41(1):22-23.

37. Reuben DB, Tinetti ME. Goal-oriented patient care-an alternative health outcomes paradigm. N Engl J Med. 2012;366(9):777-779. 